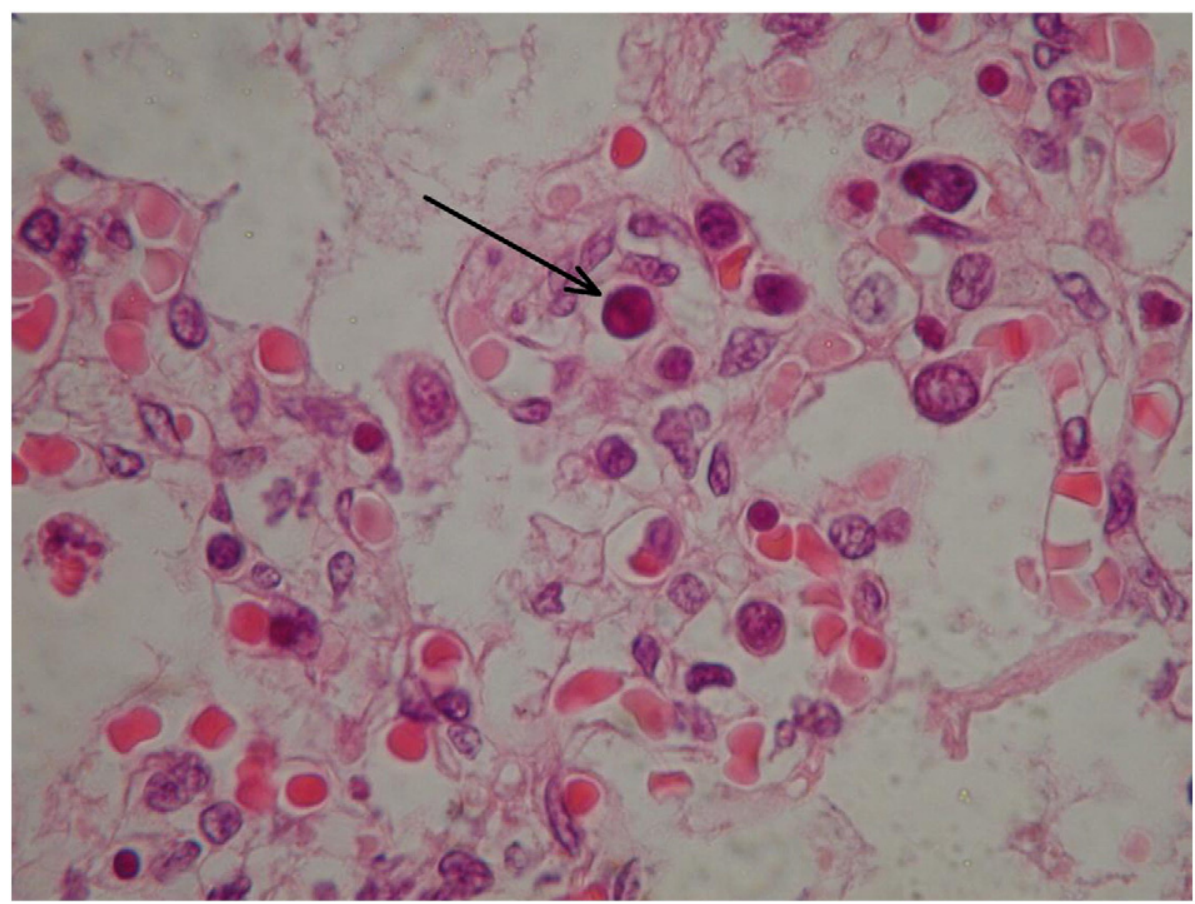

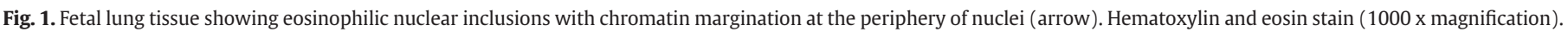

\section{References}

[1] Brkic S, Bogavac MA, Simin N, Hrnjakovic-Cvetkovic I, Milosevic V, Maric D. Unusual high rate of asymptomatic maternal parvovirus B19 infection associated with severe fetal outcome. J Matern Fetal Neonatal Med 2011;24(4):647-9.

[2] Lamont RF, Sobel JD, Vaisbuch E, Kusanovic JP, Mazaki-Tovi S, Kim SK, et al Parvovirus B19 infection in human pregnancy. BJOG 2011;118(2):175-86.
[3] Dijkmans AC, de Jong EP, Dijkmans BA, Lopriore E, Vossen A, Walther FJ, et al. Parvovirus B19 in pregnancy: prenatal diagnosis and management of fetal complications. Curr Opin Obstet Gynecol 2012;24(2):95-101.

[4] de Jong EP, de Haan TR, Kroes AC, Beersma MF, Oepkes D, Walther FJ. Parvovirus B19 infection in pregnancy. J Clin Virol 2006;36(1):1-7.

\title{
The relationship between facility-based delivery and maternal and neonatal mortality in Sub-Saharan Africa
}

\author{
Cheryl A. Moyer ${ }^{\mathrm{a}, *}$, Richard M. Adanu ${ }^{\mathrm{b}}$, Cyril M. Engmann ${ }^{\mathrm{c}}$ \\ a Global REACH and Department of Medical Education, University of Michigan Medical School, Ann Arbor, USA \\ b School of Public Health, College of Health Sciences, University of Ghana, Accra, Ghana \\ c Departments of Pediatrics and Maternal and Child Health, University of North Carolina, Chapel Hill, USA
}

\section{A R T I C L E I N F O}

\section{Article history:}

Received 16 January 2013

Received in revised form 11 April 2013

Accepted 24 May 2013

\section{Keywords:}

Facility-based delivery

Maternal mortality

Neonatal mortality

Sub-Saharan Africa

\footnotetext{
* Corresponding author at: Global REACH and Department of Medical Education, University of Michigan Medical School, 5115 Med Sci 1, 1301 Catherine Street, Ann Arbor, MI 48109, USA. Tel.: +1 734615 2838; fax: +1 7346156300 .

E-mail address: camoyer@umich.edu (C.A. Moyer).
}

Each year, approximately 275000 women die during and shortly after pregnancy, while 2.9 million infants die in the first 28 days of life [1]. The vast majority of these deaths occur in low- and middle-income countries, with disproportionately high rates in Sub-Saharan Africa.

It is estimated that having universal skilled birth attendancedefined not only by the presence of a skilled provider but also by an "enabling environment" that includes adequate supplies and a viable referral chain [2]-could reduce maternal mortality (MM) by $13 \%-33 \%$ and neonatal mortality (NM) by $20 \%-30 \%$ globally $[3,4]$.

The aim of the present study was to examine whether this estimation held true in Sub-Saharan Africa by examining the relationship between national facility-based delivery (FBD) percentages and national MM and NM ratios, including early neonatal mortality (ENM: deaths between 0 and 6 days), late neonatal mortality (LNM: deaths between 7 and 28 days), and overall neonatal mortality (deaths between 0 and 28 days).

Data for FBD were collected from the most recent Demographic and Health Surveys conducted in 36 nations in Sub-Saharan Africa. Facilitybased delivery percentages were assessed by asking women who 
reported pregnancies within the most recent Demographic and Health Survey data collection window, for each child delivered, "where did you give birth to [child's name]?" [5]. "Facility" deliveries were those that occurred at any building designed for the provision of healthcare, regardless of the size or quality of the facility. Data for MM and NM (including ENM and LNM) were collected from recently published data by Lozano et al. [1], who used surveys, censuses, vital registration, and verbal autopsy data-in combination with statistical modeling-to determine the ratio of maternal deaths per 100000 live births and the ratio of neonatal, early neonatal, and late neonatal deaths per 1000 live births.

Data were entered into Excel (Microsoft, Redmond, WA, USA) and imported into Stata/IC version 11.0 (StataCorp, College Station, TX, USA). Pearson correlation coefficients were calculated for FBD, MM, NM, ENM, and LNM. Correlations were conducted by region and stratified to include examination across all years and for 2005-2011. A P value of $\leq 0.05$ was considered to be statistically significant.

Table 1 illustrates the FBD percentages and ratios of MM and NM for 36 nations in Sub-Saharan Africa stratified by region. Table 2 illustrates the correlation coefficients when FBD percentages were compared with MM and NM ratios.

The FBD percentages were significantly negatively correlated with MM $(P=0.004), \mathrm{NM}(P=0.019)$, and LNM $(P=0.004)$. There was also a negative overall correlation of FBD and ENM; however, it was not statistically significant $(P=0.062)$. When only the data from 2005 onward were included in the analysis, FBD was significantly associated with LNM $(P=0.043)$ (Table 2$)$.
By region, western and central Africa showed the strongest relationship between FBD and ratios of MM, NM, ENM, and LNM (Table 2).

The present study demonstrated a significant relationship between higher utilization of FBD in Sub-Saharan Africa and lower MM and NM. However, this relationship seems to be attenuating over time. The study also showed that the relationship between FBD and mortality is stronger in western and central Africa than in other regions of the continent. Further research is needed to explore the factors associated with both changes over time, as well as regional variability in these associations. Additional research is also warranted to determine whether similar results would be found when looking at skilled birth attendance in general, rather than only deliveries occurring in facilities.

Correlation is not causation, and many of the factors associated with higher utilization of FBD (e.g. greater wealth, higher rates of insurance coverage, and greater female education) might also be related to lower MM and NM. The quality of available data for the variables included in the analyses is also worth addressing. Facility-based delivery was estimated based on self-reports of women, without regard for the differences in the quality of facilities attended. Furthermore, despite improvements in NM data collection and estimation in recent years, underreporting and misclassification are likely to have impacted the quality of the estimates available. It is also clear that the lack of current data on FBD rates throughout Sub-Saharan Africa hampers the ability to draw firm conclusions. Nonetheless, these preliminary findings indicate that, in Sub-Saharan Africa, global estimates hold true and regional policies and programs should continue to emphasize FBD.

Table 1

FBD percentages and ratios of MM and NM by region in Sub-Saharan Africa.

\begin{tabular}{|c|c|c|c|c|c|c|}
\hline Region & FBD, $\%$ & $\begin{array}{l}\text { MM per } 100000 \\
\text { live births }\end{array}$ & $\begin{array}{l}\text { NM per } 1000 \\
\text { live births }\end{array}$ & $\begin{array}{l}\text { ENM per } 1000 \\
\text { live births }\end{array}$ & $\begin{array}{l}\text { LNM per } 1000 \\
\text { live births }\end{array}$ & DHS year \\
\hline \multicolumn{7}{|l|}{ Eastern Africa } \\
\hline Burundi & 59.5 & 894.2 & 29.2 & 19.6 & 9.6 & 2010 \\
\hline Eritrea & 26.3 & 1081.3 & 22.1 & 17.4 & 4.7 & 2002 \\
\hline Ethiopia & 9.9 & 528.8 & 33.6 & 24.9 & 8.7 & 2011 \\
\hline Kenya & 42.6 & 294.2 & 24 & 19 & 5 & 2008 \\
\hline Madagascar & 35.3 & 424.4 & 19.2 & 14.3 & 4.9 & 2008-2009 \\
\hline Malawi & 73.2 & 421.6 & 27.2 & 20.6 & 6.6 & 2010 \\
\hline Mozambique & 47.6 & 509.8 & 38.7 & 27.9 & 10.8 & 2003 \\
\hline Rwanda & 68.9 & 335 & 25.7 & 19.8 & 5.9 & 2010 \\
\hline Tanzania & 50.2 & 417.5 & 24.3 & 18.5 & 5.8 & 2010 \\
\hline Uganda & 41.8 & 274.2 & 27.1 & 21.1 & 6 & 2006 \\
\hline Zambia & 47.7 & 293 & 26.3 & 17.6 & 8.7 & 2007 \\
\hline \multicolumn{7}{|l|}{ Western Africa } \\
\hline Benin & 78.1 & 329 & 29.3 & 23.4 & 5.9 & 2006 \\
\hline Burkina Faso & 66.3 & 353.6 & 39 & 25.5 & 13.5 & 2010 \\
\hline Cameroon & 61.2 & 531.2 & 33.9 & 25.9 & 8 & 2011 \\
\hline Cape Verde & 54.7 & 127.1 & 14 & 11 & 3 & 1998 \\
\hline Chad & 11.7 & 608.3 & 45.8 & 31.7 & 14.1 & 2004 \\
\hline Cote D'Ivoire & 47.1 & 452 & 37.5 & 26.9 & 10.6 & 1999 \\
\hline Ghana & 57.1 & 328.3 & 25 & 20.2 & 4.8 & 2008 \\
\hline Guinea & 29 & 664.1 & 39.8 & 29.2 & 10.6 & 2005 \\
\hline Liberia & 36.9 & 906 & 31.9 & 24.1 & 7.8 & 2007 \\
\hline Mali & 45.1 & 418.8 & 45.9 & 33.5 & 12.4 & 2006 \\
\hline Mauritania & 48.5 & 550.1 & 31.9 & 25.4 & 6.5 & $2000-2001$ \\
\hline Niger & 17.2 & 522.4 & 32.4 & 20.5 & 11.9 & 2006 \\
\hline Nigeria & 35 & 487.1 & 39 & 28.7 & 10.3 & 2008 \\
\hline Sao Tome and Principe & 78.8 & 266.4 & 21.3 & 17.1 & 4.2 & 2009 \\
\hline Senegal & 72.8 & 368.4 & 26.3 & 19.5 & 6.8 & 2010-2011 \\
\hline Sierra Leone & 24.6 & 616.4 & 36.4 & 27.1 & 9.3 & 2008 \\
\hline \multicolumn{7}{|l|}{ Central Africa } \\
\hline Angola & 45.7 & 334.8 & 39.2 & 28.7 & 10.5 & 2006-2007 \\
\hline Congo (Brazzaville) & 82.2 & 571.2 & 32.3 & 24.6 & 7.7 & 2005 \\
\hline Democratic Republic of the Congo & 70.1 & 480.6 & 33.4 & 25 & 8.4 & 2007 \\
\hline Gabon & 84.7 & 430.1 & 26.8 & 22.8 & 4 & 2000 \\
\hline \multicolumn{7}{|l|}{ Southern Africa } \\
\hline Lesotho & 58.7 & 238.6 & 39.2 & 30.9 & 8.3 & 2009 \\
\hline Namibia & 80.8 & 132.6 & 23 & 18.8 & 4.2 & 2006-2007 \\
\hline South Africa & 83.4 & 91.3 & 14.3 & 10.8 & 3.5 & 1998 \\
\hline Swaziland & 47.1 & 281.6 & 23.5 & 18.4 & 5.1 & $2006-2007$ \\
\hline Zimbabwe & 65.1 & 329.2 & 22.5 & 16.5 & 6 & 2010-2011 \\
\hline
\end{tabular}

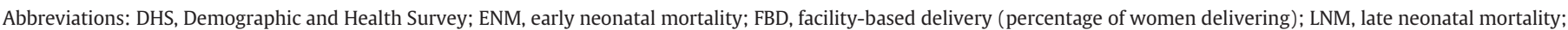
MM, maternal mortality; NM, neonatal mortality. 
Table 2

Correlation between FBD percentage and ratios of maternal and neonatal mortality in Sub-Saharan Africa.

\begin{tabular}{|c|c|c|c|c|}
\hline & $\begin{array}{l}\text { Pearson correlation } \\
\text { coefficient against FBD, } \\
\text { all years } \\
(P \text { value })\end{array}$ & $\begin{array}{l}\text { Pearson correlation } \\
\text { coefficient against FBD, } \\
2005-2011 \\
(P \text { value })\end{array}$ & $\begin{array}{l}\text { Pearson correlation } \\
\text { coefficient against FBD } \\
\text { by region, all years } \\
(P \text { value })\end{array}$ & $\begin{array}{l}\text { Pearson correlation } \\
\text { coefficient against FBD } \\
\text { by region, 2005-2011 } \\
(P \text { value })\end{array}$ \\
\hline \multirow[t]{4}{*}{ Maternal mortality ${ }^{\mathrm{a}}$} & $-0.46(0.004)$ & $-0.36(0.063)$ & West: $-0.63(0.008)$ & West: -0.69 (0.013) \\
\hline & & & East: $-0.24(0.478)$ & East: $0.04(0.919)$ \\
\hline & & & Central: $0.75(0.246)$ & Central: 0.99 (0.037) \\
\hline & & & Southern: $-0.80(0.101)$ & Southern: $-0.67(0.327)$ \\
\hline \multirow[t]{4}{*}{ Neonatal mortality ${ }^{\mathrm{b}}$} & $-0.39(0.019)$ & $-0.30(0.119)$ & West: $-0.55(0.027)$ & West: $-0.53(0.079)$ \\
\hline & & & East: $-0.04(0.912)$ & East: $-0.24(0.539)$ \\
\hline & & & Central: -0.92 (0.080) & Central: $-0.98(0.116)$ \\
\hline & & & Southern: -0.52 (0.369) & Southern: -0.23 (0.773) \\
\hline \multirow[t]{4}{*}{ Early neonatal mortality } & $-0.31(0.062)$ & $-0.22(0.254)$ & West: $-0.47(0.064)$ & West: $-0.44(0.156)$ \\
\hline & & & East: $-0.08(0.803)$ & East: $-0.26(0.496)$ \\
\hline & & & Central: -0.96 (0.034) & Central: -0.97 (0.154) \\
\hline & & & Southern: $-0.49(0.401)$ & Southern: $-0.18(0.820)$ \\
\hline \multirow[t]{4}{*}{ Late neonatal mortality ${ }^{\mathrm{b}}$} & $-0.47(0.004)$ & $-0.39(0.043)$ & West: $-0.59(0.014)$ & West: $-0.55(0.063)$ \\
\hline & & & East: $0.05(0.877)$ & East: $-0.11(0.787)$ \\
\hline & & & Central: $-0.84(0.156)$ & Central: $-0.99(0.056)$ \\
\hline & & & Southern: $-0.59(0.295)$ & Southern: -0.37 (0.627) \\
\hline
\end{tabular}

Abbreviation: FBD, facility-based delivery.

a Ratio per 100000 live births.

b Ratio per 1000 live births.

\section{Conflict of interest}

The authors have no conflicts of interest.

\section{References}

[1] Lozano R, Wang H, Foreman KJ, Rajaratnam JK, Naghavi M, Marcus JR, et al. Progress towards Millennium Development Goals 4 and 5 on maternal and child mortality: an updated systematic analysis. Lancet 2011;378(9797):1139-65.

[2] Bell J, Hussein J, Jentsch B, Scotland G, Bullough C, Graham W. Improving skilled attendance at delivery: a preliminary report of the SAFE strategy development tool. Birth 2003;30(4):227-34.
[3] Darmstadt GL, Bhutta ZA, Cousens S, Adam T, Walker N, de Bernis L, et al. Evidencebased, cost-effective interventions: how many newborn babies can we save? Lancet 2005;365(9463):977-88.

[4] Graham WJ, Bell JS, Bullough $\mathrm{CH}$. Can skilled attendance at delivery reduce maternal mortality in developing countries? In: Brouwere V, Van Lerberghe W, editors. Safe Motherhood Strategies: a Review of the Evidence. , Studies in Health Services Organisation and PolicyAntwerp: ITG Press; 2001. p. 97-130.

[5] Measure DHS. DHS Survey Indicators - Maternal and Child Health. http://www. measuredhs.com/data/DHS-Survey-Indicators-Maternal-and-Child-Health.cfm. Accessed April 8, 2013.

\title{
Bakri balloon tamponade for the management of postpartum hemorrhage
}

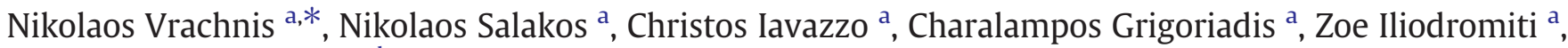 \\ Charalampos Siristatidis ${ }^{\mathrm{b}}$, Christos Katsetos ${ }^{\mathrm{c}}$, George Creatsas ${ }^{\text {a }}$ \\ a Second Department of Obstetrics and Gynecology, University of Athens Medical School, Aretaieion Hospital, Athens, Greece \\ b Third Department of Obstetrics and Gynecology, University of Athens Medical School, Attiko Hospital, Athens, Greece \\ c Department of Obstetrics and Gynecology, Tzaneio General Hospital of Piraeus, Piraeus, Greece
}

\section{A R T I C L E I N F O}

\section{Article history:}

Received 6 January 2013

Received in revised form 24 March 2013

Accepted 22 May 2013

\section{Keywords:}

Advanced Life Support in Obstetrics

Bakri balloon

Intrauterine balloon tamponade

Postpartum hemorrhage

Uterine atony

\footnotetext{
* Corresponding author at: Second Department of Obstetrics and Gynecology, University of Athens Medical School, Aretaieion Hospital, 124B Vasilisis Sofias Av., 11526 Athens, Greece. Tel.: + 30 6974441144; fax: + 302107777390 .

E-mail address: nvrachnis@hotmail.com (N. Vrachnis).
}

Postpartum hemorrhage (PPH) remains the main cause of maternal death worldwide (associated with a mortality rate of approximately 140000 deaths per year). Obstetric hysterectomywhich is the last resort in the management of PPH-occurs in 0.35 per 1000 births [1].

If conservative management of PPH fails, surgical treatment is needed. Ligation of uterine or internal iliac arteries, application of uterine compressive sutures (B-Lynch), and hysterectomy can be performed in order to control massive PPH and restore hemodynamic stability. However, obstetric hysterectomy is an undesirable method, especially among primiparas, because it leads to irreversible loss of fertility. Hence the growing attraction of new conservative techniques such as the Bakri intrauterine balloon tamponade, which is associated with high success rates.

The present paper reports on a case series of women diagnosed with PPH who underwent Bakri balloon tamponade between January 1, 2008, and December 31, 2011. Because Bakri balloon is not the 